Check for updates

Cite this: RSC Adv., 2018, 8, 18008

\title{
DFT prediction of a novel molybdenum tetraboride superhard material
}

\begin{abstract}
Yong Pan, (D) *a Xiaohong Wang, ${ }^{a}$ Songxia $\mathrm{Li}{ }^{\mathrm{a}}$ Yanqiong $\mathrm{Li}^{\mathrm{b}}$ and Ming Wen ${ }^{\mathrm{b}}$
Although transition metal borides (TMBs) are promising superhard materials, the research and development of new TMB superhard materials is still a great challenge. Naturally, the Vickers hardness of TMBs is related to the 3D-network chemical bonding, in addition to the valence electron density and covalent bonds. In this paper, we apply ab initio calculations to explore the structural stability, Vickers hardness and hardening mechanism of $\mathrm{MoB}_{4}$ tetraboride. Four possible tetraborides are predicted based on the phonon dispersion model. We find that $\mathrm{MoB}_{4}$ with monoclinic structure $(\mathrm{C} 2 / \mathrm{m})$ and orthorhombic structure $(/ \mathrm{mmm})$ are dynamically stable at the ground state. The calculated Vickers hardness of $\mathrm{MoB}_{4}$ with monoclinic and orthorhombic structures is $41.3 \mathrm{GPa}$ and $40.0 \mathrm{GPa}$, respectively. We suggest that the high hardness is derived from the 3D-network $\mathrm{B}-\mathrm{B}$ covalent bond owing to bond synergistic effects. On the other hand, the Vickers hardness of $\mathrm{MoB}_{4}$ decreases gradually with increasing pressure. The calculated results show that the hardness of $\mathrm{MoB}_{4}$ is attributed to the $B / G$ ratio and c/a ratio. Finally, we predict that $\mathrm{MoB}_{4}$ is a new superhard material.
\end{abstract}

Received 16th March 2018

Accepted 30th April 2018

DOI: $10.1039 / \mathrm{c} 8 \mathrm{ra02324g}$

rsc.li/rsc-advances

sensitive to the concentration of the alloying element. Kaner

\section{Introduction}

The research and development of new superhard materials is still a growing interest owing to the increasing demand for their industrial applications. Among all the superhard materials, transition metal borides (TMBs) are attractive and promising candidates because of their high Vickers hardness, high elastic modulus, excellent thermal stability and electronic properties etc. ${ }^{1-9}$ Over the last few years, a large number of TMBs have been widely investigated..$^{10-15}$ Despite some TMBs being potential superhard materials, ${ }^{16,17}$ controversy remains about the intrinsic hardness of TMBs. One is that the measured Vickers hardness of TMBs fails to agree with the theoretical results. ${ }^{18}$ The other important reason is that numerous TMBs are not superhard materials because of theirs structural features and bonding characteristics. ${ }^{19-22}$

To explore new superhard materials, recent works have proposed that alloying is a good path to improve the hardness of TMBs. ${ }^{23,24}$ The Vickers hardness of $\mathrm{WB}_{4}$ with alloying elements of 6 at $\% \mathrm{Hf}, 8$ at $\% \mathrm{Zr}$ and 8 at $\%$ Ti increases from $43.3 \mathrm{GPa}$ to $51.6 \mathrm{GPa}, 55.9 \mathrm{GPa}$ and $50.9 \mathrm{GPa}$, respectively. ${ }^{17}$ The measured Vickers hardness of $\mathrm{Y}_{0.5} \mathrm{Sc}_{0.5} \mathrm{~B}_{12}, \mathrm{Zr}_{0.5} \mathrm{Sc}_{0.5} \mathrm{~B}_{12}$ and $\mathrm{Zr}_{0.5} \mathrm{Y}_{0.5} \mathrm{~B}_{12}$ is $45.2 \mathrm{GPa}, 48.0 \mathrm{GPa}$ and $45.8 \mathrm{GPa}$, respectively. ${ }^{25}$ Low concentration of Mo can effectively improve the Vickers hardness of $\mathrm{WB}_{4}{ }^{26}$ However, the Vickers hardness of ternary borides is

${ }^{a}$ School of Material Science and Engineering, Southwest Petroleum University, Chengdu 610500, China. E-mail: panyong10@mails.jlu.edu.cn; Fax: +86-02883037406; Tel: +86-028-83037401

${ }^{b}$ State Key Laboratory of Advanced Technologies for Comprehensive Utilization of Platinum Metals, Kunming, 650106, China et al. have found that high concentration of Re weakens the Vickers hardness of $\mathrm{WB}_{4} \cdot{ }^{26} \mathrm{In}$ particular, the hardening mechanism of ternary boride becomes very complex due to the charge interaction between elements. The development of ternary TMBs superhard material is faced with the great challenge. Thus, the search for binary TMBs superhard material is still of great significant.

According to the equation of Vickers hardness: $H_{\mathrm{V}}=$ $1854.4 P / d^{2}$, it is clear that the hardness of a solid is determined by the applied load and indent mark in micrometer. Thus, we suggest that the Vickers hardness of TMBs depends on the chemical bonding of the direction of applied load, in addition to the valence electron density and covalent bond. There is no doubt that 3D-network chemical bonding can effectively improve the incompressibility and hardness. For example, although the valence electron density of $3 \mathrm{~d}-\mathrm{Cr}$ and $4 \mathrm{~d}-\mathrm{Zr}$ is smaller than that of $5 \mathrm{~d}-\mathrm{W}$ and $5 \mathrm{~d}-\mathrm{Re}, \mathrm{CrB}_{4}$ and $\mathrm{ZrB}_{4}$ can be regarded as potential superhard materials due to the 3Dnetwork B-B covalent bond. ${ }^{27,28}$ As mentioned above, tetraboride with 3D boron network is expected to show superhardness. Unfortunately, the structural stability of tetraborides is still a great dilemma for the development of TMBs superhard materials.

We report on a new $\mathrm{MoB}_{4}$ tetraboride and those structural features influence the intrinsic hardness of $\mathrm{MoB}_{4}$. The likely hardening mechanism behind the hardness vs. pressure is provided in these cases. We predict that $\mathrm{MoB}_{4}$ with monoclinic $\mathrm{C2} / \mathrm{m}$ structure and orthorhombic $\mathrm{Immm}$ structure are new superhard material. Importantly, we propose that the intrinsic 
hardness of TMBs is attributed to arrangement of chemical bonding along the applied load, which is related to the $c / a$ ratio and $B / G$ ratio.

\section{Models and theoretical methods}

To guarantee the $3 \mathrm{D}$ boron network, tetraboride is a very attractive structure. As we know, $\mathrm{WB}_{4}$ with hexagonal structure (space group: $\mathrm{Pb}_{3} / \mathrm{mmc}$ ) is a tetraboride. ${ }^{29}$ In this structure, $\mathrm{W}$ atoms occupy the Wyckoff $2 b(0,0,0.2500)$ and $2 c(0.6667$, $0.3333,0.7500)$ sites, and B atoms locate at the $12 i(0,0.3347,0)$ and $4 f(0.6653,0.6653,0.500)$ sites, respectively. It is observed that hexagonal prism is composed of $12 \mathrm{~B}$ atoms, which can improve the deformation resistance and intrinsic hardness. Although the calculated Vickers hardness of $\mathrm{WB}_{4}$ is about 46.2 $\mathrm{GPa}$, this structure is unstable at the ground state. ${ }^{30-32} \mathrm{On}$ the other hand, other $\mathrm{TMB}_{4}(\mathrm{TM}=\mathrm{Re}$, Mo and $\mathrm{Os})$ with $\mathrm{WB}_{4^{-}}$ type structures are not superhard materials.

According to the above design principles, we find that the existences of $\mathrm{CrB}_{4}$ with orthorhombic structure (Immm) ${ }^{33} \mathrm{ZrB}_{4}$ with orthorhombic structure $(\mathrm{Cmcm})^{28,34}$ and $\mathrm{MnB}_{4}$ with monoclinic structure $(C 2 / m)^{35}$ have the $3 \mathrm{D}$ boron network, which may improve the deformation resistance and enhance the intrinsic hardness. Therefore, in this paper, we consider and design these tetraborides. The structural models of $\mathrm{MoB}_{4}$ with four possible structures are shown in Fig. 1.

According to the Inorganic Crystal Structure Database (ISCD), we apply this idea to investigate potential structure of $\mathrm{MoB}_{4}$. Four structures were considered: $\mathrm{WB}_{4}$-type structure $\left(\mathrm{PG}_{3} / \mathrm{mmc}\right), \mathrm{ZrB}_{4}$-type structure $(\mathrm{Cmcm}), \mathrm{MnB}_{4}$-type structure ( $\mathrm{C2} /$ $\mathrm{m}$ ) and $\mathrm{CrB}_{4}$-type structure (Immm), respectively. All calculations in this paper were performed by using the DFT within generalized-gradient-approximation (GGA) with PBE functional, ${ }^{36}$ as implemented in CASTEP code. ${ }^{37}$ The interactions between the electrons and ions were adopted by using the ultrasoft pseudopotential. ${ }^{38}$ In addition, the electronic configurations of Mo atom and B atom were $4 \mathrm{p}^{6} 4 \mathrm{~d}^{5} 5 \mathrm{~s}^{1}$ and $2 \mathrm{~s}^{2} 2 \mathrm{p},{ }^{1}$ respectively. After the converged test, the cutoff energy of plane wave was $400 \mathrm{eV}$. The $k$-point grids of $11 \times 11 \times 8,17 \times 17 \times 5$, $13 \times 13 \times 19$ and $18 \times 18 \times 13$ for $\mathrm{WB}_{4}{ }^{- \text {type structure, } \mathrm{ZrB}_{4}{ }^{-}}$ type structure, $\mathrm{MnB}_{4}$-type structure, and $\mathrm{CrB}_{4}$-type structure were treated, respectively. During the structural optimization, the periodic boundary condition (PBC) of a system was adopted and all atoms in a system were fully relaxed. In this paper, the elastic properties of $\mathrm{MoB}_{4}$ were calculated by the stress tensor vs. strain method. ${ }^{39,40}$ The dynamically stable of $\mathrm{MoB}_{4}$ is estimated by the PHONON code. Importantly, the Vickers hardness $\left(H_{\mathrm{V}}\right)$ of $\mathrm{MoB}_{4}$ is given by: ${ }^{41}$

$$
H_{\mathrm{V}}=2\left(k^{2} G\right)^{0.585}-3
$$

where $G$ and $k$ are the shear modulus and $G / B$ (B: bulk modulus), respectively.

\section{Results and discussion}

The structural stability of a boride is determined not only by the thermodynamically stable but also by the dynamically stable. ${ }^{42,43}$ Although the structural information and mechanical properties of $\mathrm{MoB}_{4}$ with $\mathrm{WB}_{4}$-type hexagonal structure have been studied over the last years, ${ }^{44-46}$ the dynamically stable of $\mathrm{MoB}_{4}$ is unknown. Therefore, we are not sure that $\mathrm{MoB}_{4}$ is stable at the ground state. To investigate the stable structure, following, we consider the formation enthalpy and phonon dispersion of $\mathrm{MoB}_{4}$ with four structures based on ab initio calculations.

Table 1 lists the calculated lattice parameters, $c / a$ ratio, density, formation enthalpy and bond length of $\mathrm{MoB}_{4}$. We can see that the calculated formation enthalpy of these structures is smaller than zero, indicating that these structures are thermodynamically stable at the ground state. Importantly, the calculated formation enthalpy of $\mathrm{MoB}_{4}$ with $\mathrm{WB}_{4}$-type hexagonal structure is about $-7.3598 \mathrm{eV}$ per atom, which is bigger than that of $\mathrm{ZrB}_{4}$-type, $\mathrm{MnB}_{4}$-type and $\mathrm{CrB}_{4}$-type structures. Therefore, we can conclude that our predicted $\mathrm{MoB}_{4}$ structure is more thermodynamically stable than that of $\mathrm{WB}_{4}$-type structure.

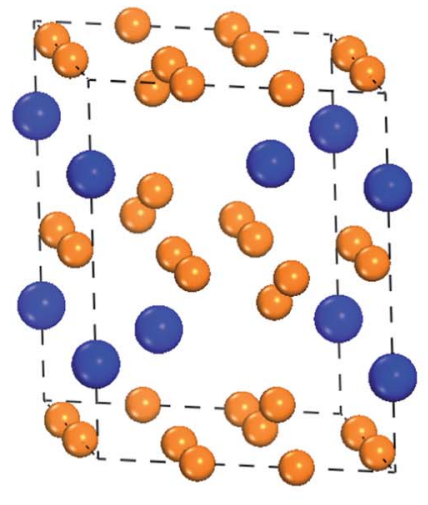

(a)

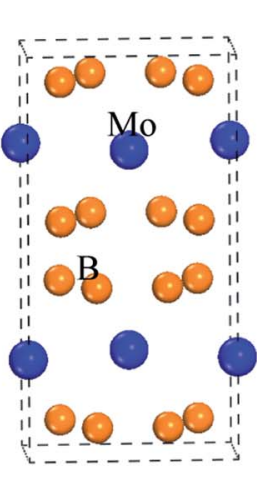

(b)

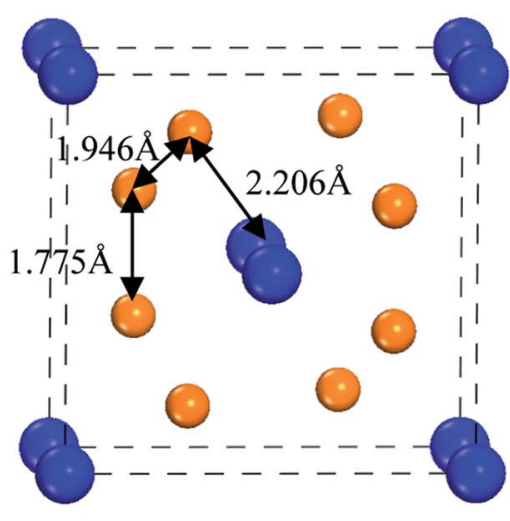

(c)

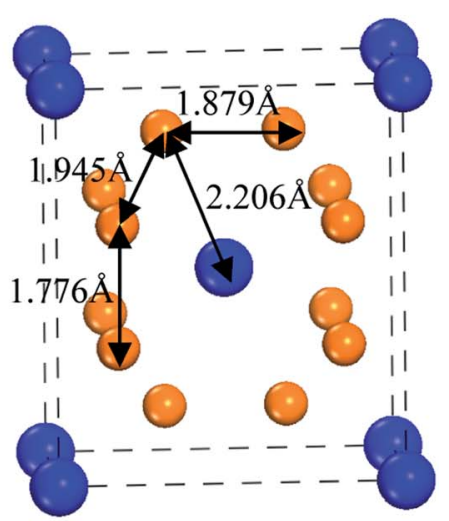

(d)

Fig. 1 The structural models of $M_{0 B}$ with four structures. (a) $W_{4}$ with hexagonal structure $\left(P 6_{3} / m m c\right)$, (b) ZrB $\mathrm{B}_{4}$ with orthorhombic structure $(\mathrm{Cmcm})$, (c) $\mathrm{MnB}_{4}$ with monoclinic structure $(\mathrm{C} 2 / \mathrm{m})$, and (d) $\mathrm{CrB}_{4}$ with orthorhombic structure $(/ \mathrm{mmm})$, respectively. 
Table 1 Calculated lattice parameters, a-axis, b-axis and c-axis $(\AA \AA), c / a$ ratio, density, $\rho\left(\mathrm{g} \mathrm{cm}^{-3}\right)$, formation enthalpy, $E_{\mathrm{f}}(\mathrm{eV}$ per atom), bond length $(\AA)$ of $\mathrm{MoB}_{4}$

\begin{tabular}{|c|c|c|c|c|c|c|c|c|c|}
\hline \multirow[t]{2}{*}{$\mathrm{WB}_{4}$-type } & Cal & 5.279 & & 6.591 & 1.249 & 5.81 & -7.3598 & 1.691 & 2.405 \\
\hline & $\operatorname{Exp}^{47}$ & 5.214 & & 6.358 & & & & & \\
\hline $\mathrm{MnB}_{4}$-type & Cal & 5.785 & 5.767 & 2.959 & 0.511 & 5.45 & -7.7949 & 1.775 & 2.206 \\
\hline $\mathrm{CrB}_{4}$-type & Cal & 4.973 & 5.767 & 2.959 & 0.595 & 5.45 & -7.7947 & 1.776 & 2.206 \\
\hline
\end{tabular}

In addition to thermodynamically stable, dynamically stable also plays a key role in structural stability. To examine the dynamically stable, Fig. 2 shows the calculated phonon dispersion curves of $\mathrm{MoB}_{4}$ with four structures. It is found that the experimental $\mathrm{MoB}_{4}$ with hexagonal structure is a dynamically unstable because there are some imaginary phonon frequencies in this structure. This result is consistent with the previous viewpoint. ${ }^{46}$ In addition, $\mathrm{ZrB}_{4}$-type structure is also a dynamically unstable at the ground state. Importantly, we find that $\mathrm{MoB}_{4}$ with $\mathrm{MnB}_{4}$-type and $\mathrm{CrB}_{4}$-type structures are dynamically stable because no imaginary phonon frequencies are observed in the two structures. As mentioned above, we can conclude that $\mathrm{MoB}_{4}$ with $\mathrm{MnB}_{4}$-type and $\mathrm{CrB}_{4}$-type structures are stable.
Obviously, we suggest that the structural stability of $\mathrm{MoB}_{4}$ is related to the structural feature and chemical bonding. As listed in Table 1 , the calculated lattice parameters of $\mathrm{WB}_{4}$-type structure are $a=5.279 \AA$ and $c=6.591 \AA$, respectively, which are in good agreement with experimental data. ${ }^{47}$ This structural feature is similar to the $\mathrm{WB}_{4}{ }^{48}$ The calculated bond length of B-B covalent bond and Mo-B bond is about $1.691 \AA$ and $2.405 \AA$, which are in excellent agreement with the other theoretical result. ${ }^{44}$

For $\mathrm{MnB}_{4}$-type structure, the calculated lattice parameters are $a=5.785 \AA, b=5.767 \AA$ and $c=2.959 \AA$, respectively. In this structure, Mo atom occupies the Wyckoff $2 a(0,0,0)$ site, and B atom locates at the $8 j(0.1889,0.3461,0.1889)$ site, respectively. For $\mathrm{CrB}_{4}$-type structure, the calculated lattice parameters are

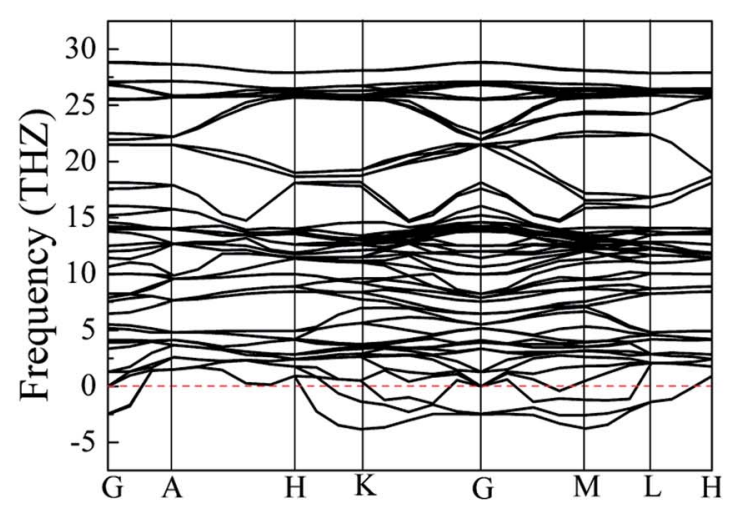

(a) $\mathrm{WB}_{4}$-type

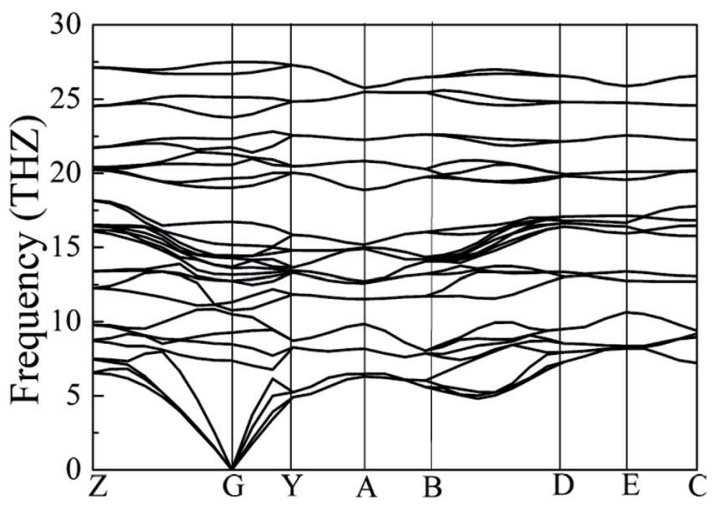

(c) $\mathrm{MnB}_{4}$-type

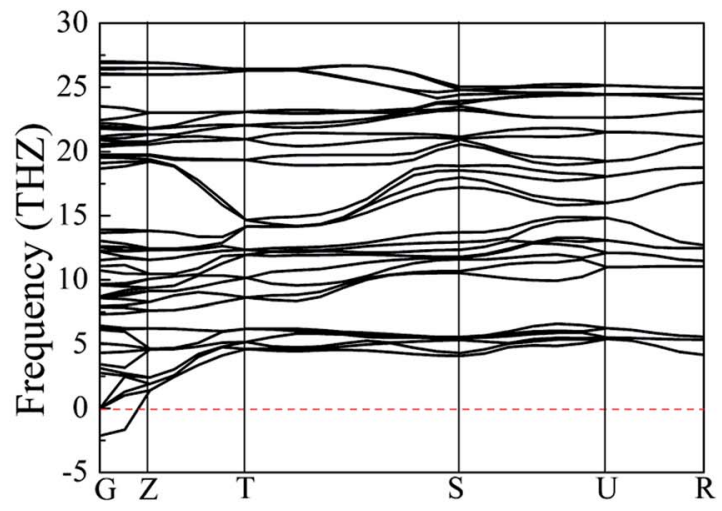

(b) $\mathrm{ZrB}_{4}$-type

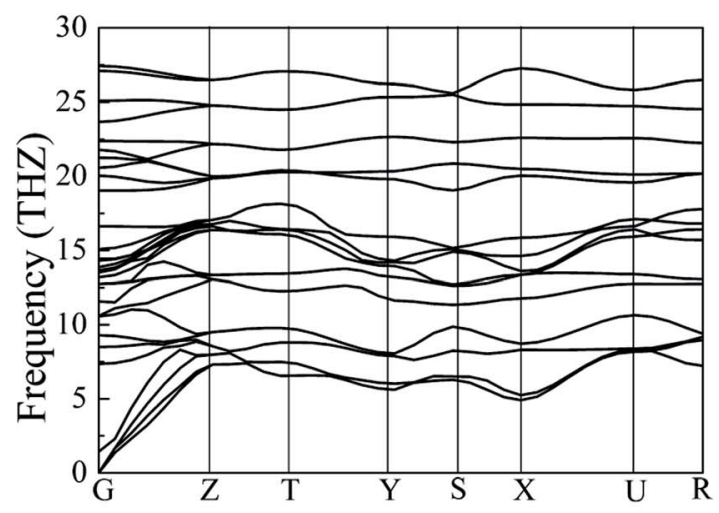

(d) $\mathrm{CrB}_{4}$-type

Fig. 2 Calculated phonon dispersion curves of $\mathrm{MoB}_{4}$, (a) $\mathrm{WB}_{4}$ with hexagonal structure, (b) $\mathrm{ZrB}_{4}$ with orthorhombic structure, (c) MnB $\mathrm{B}_{4}$ with monoclinic structure and (d) $\mathrm{CrB}_{4}$ with orthorhombic structure, respectively. 
$a=5.785 \AA, b=5.767 \AA$ and $c=2.959 \AA$, respectively. In this structure, Mo atom occupies the Wyckoff $2 a(0,0,0)$ site, and B atom locates at the $8 n(0.1889,0.6540,0)$ site, respectively. Obviously, the $\mathrm{B}$ atom positions in $\mathrm{CrB}_{4}$-type structure are shifted in comparison to $\mathrm{MnB}_{4}$-type structure. The structural discrepancy is shown in Fig. 1.

Although the structural feature of $\mathrm{MnB}_{4}$-type and $\mathrm{CrB}_{4}$-type structures is similar, the structural feature of $\mathrm{MnB}_{4}$-type and $\mathrm{CrB}_{4}$-type structures is different from the $\mathrm{WB}_{4}$-type structure. From Fig. 1, we can see that the bond cage of $\mathrm{CrB}_{4}$-type structure is composed of $12 \mathrm{~B}$ atoms. Note that Mo atom locates at the center of the $\mathrm{B}$ bond cage. This structural feature is very similar to the $\mathrm{CrB}_{4}{ }^{49}$ Therefore, the 3D-network B-B covalent bond can improve the structural stability and mechanical properties. However, the structural feature of $\mathrm{MnB}_{4}$-type structure is slightly different from $\mathrm{CrB}_{4}$-type structures. The $\mathrm{B}$ atom migration adjusts the $\mathrm{B}$ bond cage, which is composed of $10 \mathrm{~B}$ atoms. As a result, the atomic configuration changes the charge interaction between $\mathrm{B}$ atoms, and alters the properties.

To explore the Vickers hardness of $\mathrm{MoB}_{4}$, Fig. 3 shows the calculated Vickers hardness of $\mathrm{MoB}_{4}$ as a function of pressure (0-100 GPa). Based on the structural stability, we consider two stable $\mathrm{MoB}_{4}$ structures: $\mathrm{MnB}_{4}$-type and $\mathrm{CrB}_{4}$-type structures, respectively. Surprisingly, the calculated Vickers hardness of $\mathrm{MnB}_{4}$-type structure and $\mathrm{CrB}_{4}$-type structure is about $41.3 \mathrm{GPa}$ and $40.0 \mathrm{GPa}$, respectively, which are much bigger than that of $\mathrm{WB}_{4}$-type structure $(24.8 \mathrm{GPa}){ }^{44}$ This result is demonstrated by the elastic modulus and $B / G$ ratio. ${ }^{50}$ The calculated bulk modulus of $\mathrm{MnB}_{4}$-type structure and $\mathrm{CrB}_{4}$-type structure is $279.1 \mathrm{GPa}$ and $279.5 \mathrm{GPa}$, respectively, which is slightly smaller than that of $\mathrm{WB}_{4} \cdot{ }^{51}$ However, the calculated shear modulus of $\mathrm{MnB}_{4}$-type structure and $\mathrm{CrB}_{4}$-type structure is $249.6 \mathrm{GPa}$ and $245.7 \mathrm{GPa}$, respectively. The calculated Young's modulus of $\mathrm{MnB}_{4}$-type structure and $\mathrm{CrB}_{4}$-type structure is $576.8 \mathrm{GPa}$ and $570.1 \mathrm{GPa}$, respectively. Obviously, the calculated shear modulus and Young's modulus of $\mathrm{MoB}_{4}$ are larger than that of $\mathrm{WB}_{4}$, implying that $\mathrm{MoB}_{4}$ has a strong shear deformation resistance and high elastic stiffness in comparison to $\mathrm{WB}_{4}$.

In addition, the Vickers hardness of TMBs is indirectly measured by the $B / G$ ratio. The general trend is, the smaller the $B / G$ ratio, the higher the hardness for a solid. According to the $a b$ initio calculations, the calculated $B / G$ ratio of $\mathrm{MnB}_{4}$-type

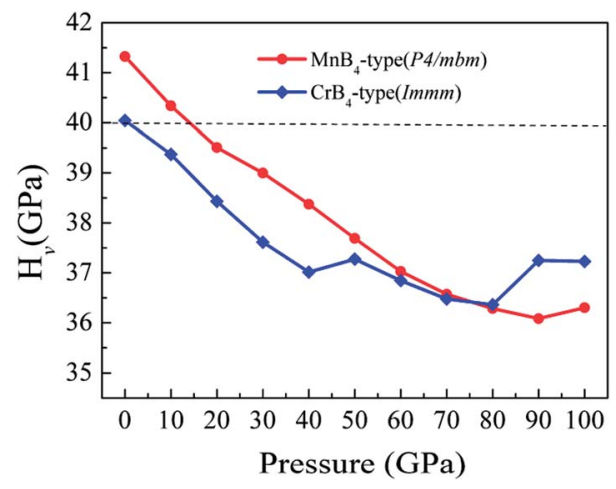

Fig. 3 Calculated Vickers hardness of $\mathrm{MoB}_{4}$ as a function of pressure. structure and $\mathrm{CrB}_{4}$-type structure is 1.12 and 1.14, respectively, which is smaller than that of $\mathrm{WB}_{4}$ hexagonal structure (1.22). ${ }^{52}$ This result also affirms that the Vickers hardness of our predicted $\mathrm{MoB}_{4}$ structure is higher than that of $\mathrm{WB}_{4}$.

According to the structural feature (see Fig. 1), we suggest that the high hardness of $\mathrm{MoB}_{4}$ with these structures is mainly determined by the 3D-network B-B covalent bond. For $\mathrm{CrB}_{4}$-type structures, B12 bond cage (12 B atoms) is composed of three different B-B covalent bonds, which can effectively improve the deformation resistance under applied load. Although the structural feature of $\mathrm{MnB}_{4}$-type structure is slightly different from $\mathrm{CrB}_{4}$-type structure, $\mathrm{B} 8$ bond cage ( $8 \mathrm{~B}$ atoms) is composed of two different B-B covalent bonds (1.775 $\AA$ and $1.946 \AA)$ and one type of Mo-B bond (2.206 $⿱$ A). As a result, this structural feature can improve the Vickers hardness of $\mathrm{MoB}_{4}$. As mentioned above, it is concluded that our predicted $\mathrm{MoB}_{4}$ tetraboride is a promising superhard material.

To gain further insight into chemical bonding, Fig. 4 shows the calculated total and partial density of states (DOS) of $\mathrm{MoB}_{4}$ with two structures. The black vertical dashed of DOS indicates the Fermi level $\left(E_{\mathrm{F}}\right)$. The calculated DOS profiles show that the some bands across the $E_{\mathrm{F}}$, meaning that $\mathrm{MoB}_{4}$ exhibits the
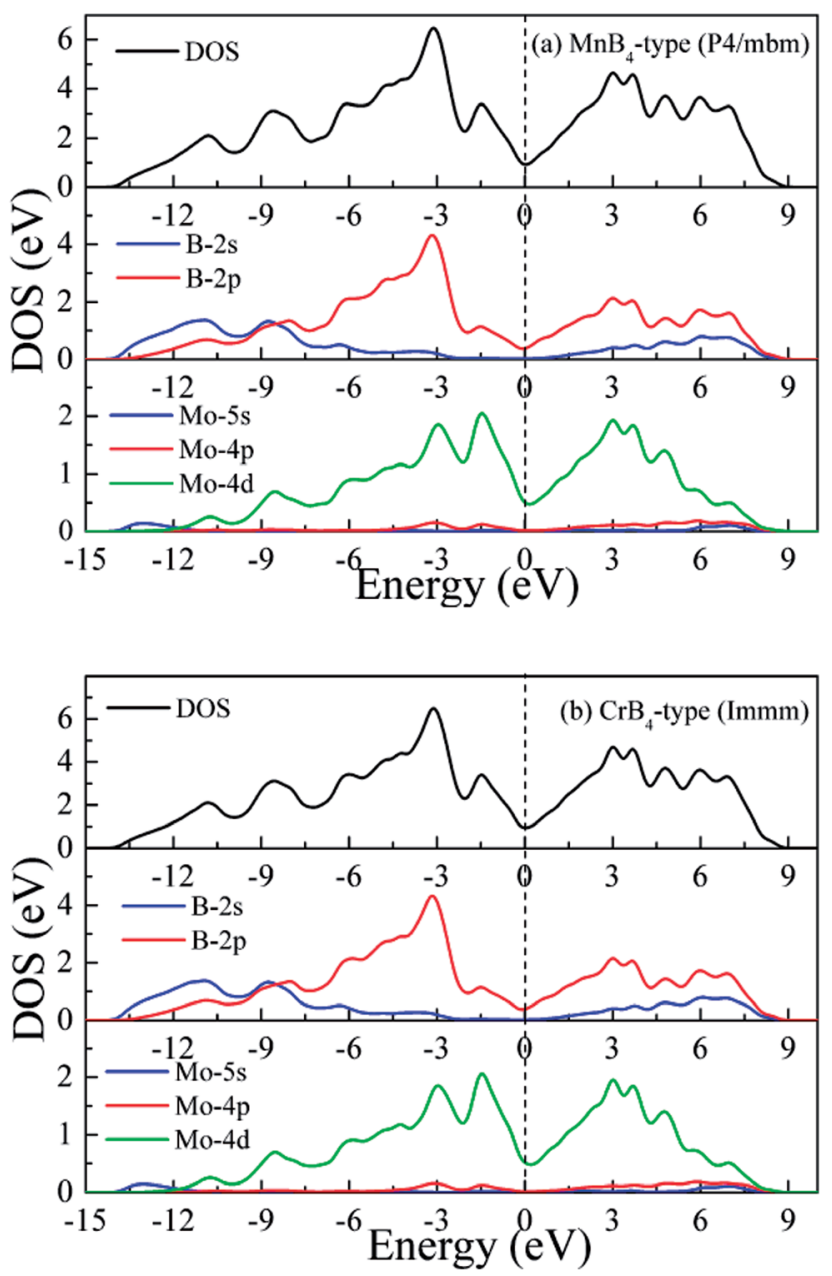

Fig. 4 Calculated DOS of $\mathrm{MoB}_{4}$, (a) $\mathrm{MnB}_{4}$-type structure and (b) $\mathrm{CrB}_{4}$ type structure, respectively. 

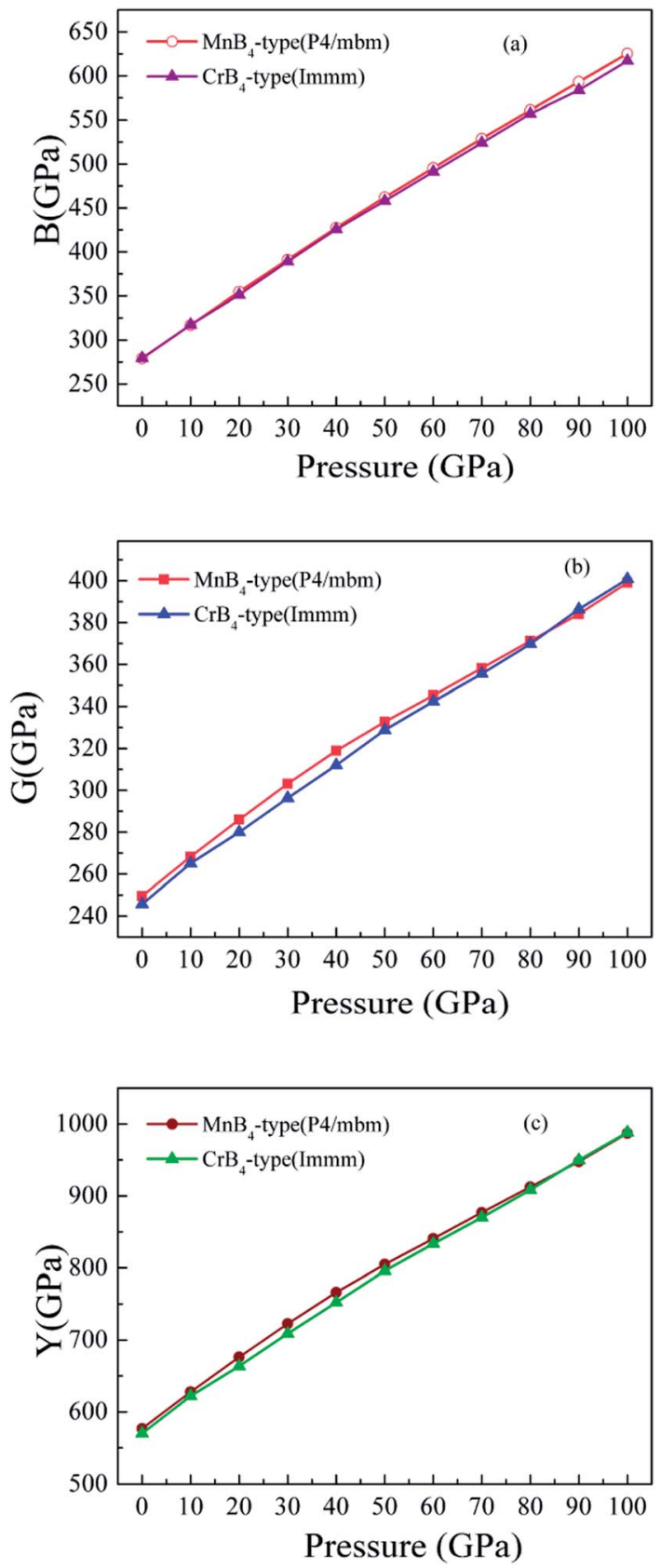

Fig. 5 Calculated elastic modulus of $\mathrm{MoB}_{4}$ as a function of pressure. (a) Bulk modulus vs. pressure, (b) shear modulus vs. pressure, and (c) Young's modulus vs. pressure, respectively.

degree of metallic behavior. This result is demonstrated by the band structure. Importantly, we can see that the DOS profile of $\mathrm{MoB}_{4}$ is contributed by Mo-4d state, B-2s state and B-2p state. The localized hybridization between Mo atom and the $\mathrm{B}$ atom forms the Mo-B bond (see Table 1). It is worth noticing that B-2s state embeds into B-2p state. As a result, the localized hybridization between $\mathrm{B}$ atoms can form the B-B covalent bond. In particular, the 3D-network $\mathrm{B}-\mathrm{B}$ covalent bonds improve the intrinsic hardness of $\mathrm{MoB}_{4}$.

On the other hand, we further find that the calculated Vickers hardness of $\mathrm{MoB}_{4}$ decreases gradually with increasing pressure. In particular, the calculated Vickers hardness of $\mathrm{MoB}_{4}$ is smaller than $40 \mathrm{GPa}$ when pressure is bigger than $10 \mathrm{GPa}$. This result indicates that pressure can weaken the Vickers hardness of $\mathrm{MoB}_{4}$, which is consistent with the previous experimentally. ${ }^{\mathbf{1 3 , 1 7}}$ However, the trend of Vickers hardness of $\mathrm{MoB}_{4}$ is different from the variation of elastic modulus. To examine the correlation between elastic modulus and the pressure, Fig. 5 displays the calculated bulk modulus, shear modulus and Young's modulus of $\mathrm{MoB}_{4}$ as a function of pressure. It is obvious that the calculated elastic modulus of $\mathrm{MoB}_{4}$ increases with increasing pressure. We suggest that this trend is attributed to the chemical bonding.

Fig. 6 shows the calculated bond length of B-B covalent bond and Mo-B bond as a function of pressure. With increasing pressure, the calculated bond length of $\mathrm{B}-\mathrm{B}$ covalent bond and Mo-B bond decrease. That is to say, high pressure obviously improves the coulomb repulsion and shorter core electron overlap, which leads to lattice shrinkage. This is why pressure enhances the elastic modulus of $\mathrm{MoB}_{4}$. However, the variation of elastic modulus does not demonstrates the trend of Vickers hardness. Therefore, we suggest that the variation of Vickers hardness of TMBs is related to other factors.

It is worth noting that the Vickers hardness of $\mathrm{MoB}_{4}$ is indirectly reflected by the $B / G$ ratio (brittle or ductile behavior). To reveal the Vickers hardness, Fig. 7 shows the calculated $B / G$ ratio of $\mathrm{MoB}_{4}$ as a function of pressure. It is obvious that the calculated $B / G$ ratio of $\mathrm{MoB}_{4}$ increases with increasing pressure.
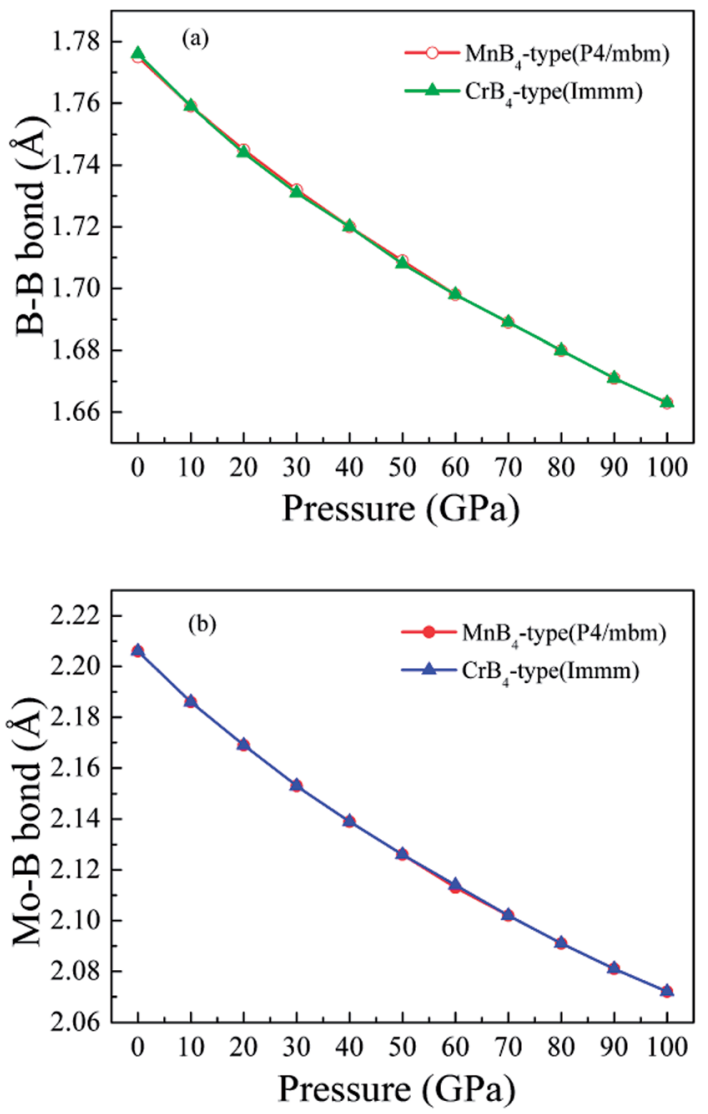

Fig. 6 Calculated bond length of chemical bonding as a function of pressure. (a) B-B covalent bond, and (b) Mo-B bond, respectively. 


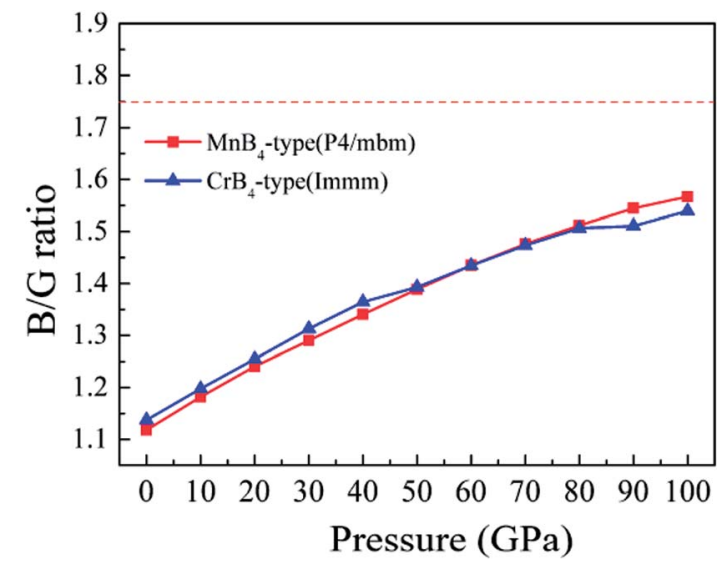

Fig. 7 Calculated $B / G$ ratio of $M_{0 B}$ as a function of pressure.

The trend is similar to the Vickers hardness. Although $\mathrm{MoB}_{4}$ shows the brittle behavior with increasing pressure, pressure weakens the brittle behavior. It indirectly affirms that high pressure reduces the Vickers hardness of $\mathrm{MoB}_{4}$.

Importantly, the Vickers hardness of a material is determined by the indent mark in micrometer based on the equation of Vickers hardness. For a solid, the volume deformation resistance and shear deformation resistance are related to the $a$ axis and $c$-axis, respectively. This is why the bulk modulus and shear modulus does not reflect the Vickers hardness of a solid. Therefore, we assume that the trend of Vickers hardness is related to the $c / a$ ratio because the $c / a$ ratio reflects the degree of deformation resistance. To demonstrate the idea, Fig. 8 shows the calculated $c / a$ ratio of $\mathrm{MoB}_{4}$ as a function of pressure. It is found that the calculated $c / a$ ratio of $\mathrm{MoB}_{4}$ decreases with increasing pressure. Therefore, high pressure aggravates the coulomb repulsion between Mo atom and the $\mathrm{B}$ atom along the $c$-axis. According to the Vickers principles, $c$-axis is just the direction of applied load. That is to say, the Vickers hardness of a solid mainly depends on the bond strength of chemical bonding along the $c$-axis. Owing to bond synergistic effects, the 3D-network B-B covalent bond can improve the deformation resistance. From Fig. 8, we can see that the calculated $c / a$ ratio of $\mathrm{MnB}_{4}$-type structure is smaller than that of $\mathrm{CrB}_{4}$-type structures. The result is related to the bonding state along the $c$-axis

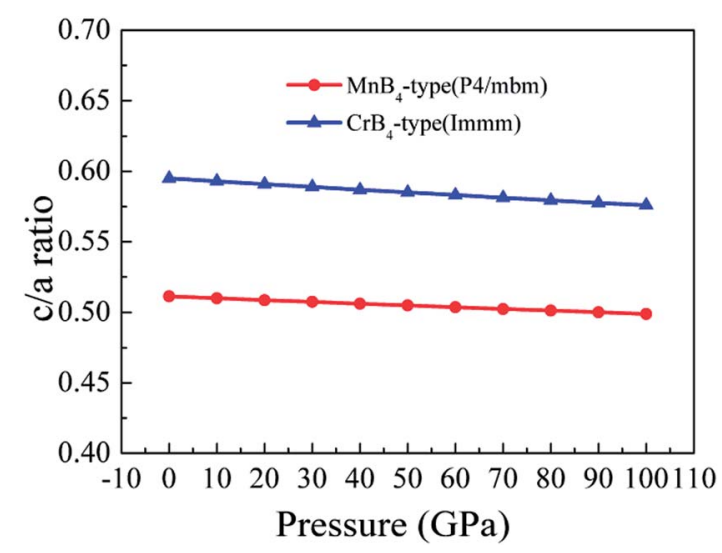

Fig. 8 Calculated c/a ratio of $\mathrm{MoB}_{4}$ as a function of pressure.

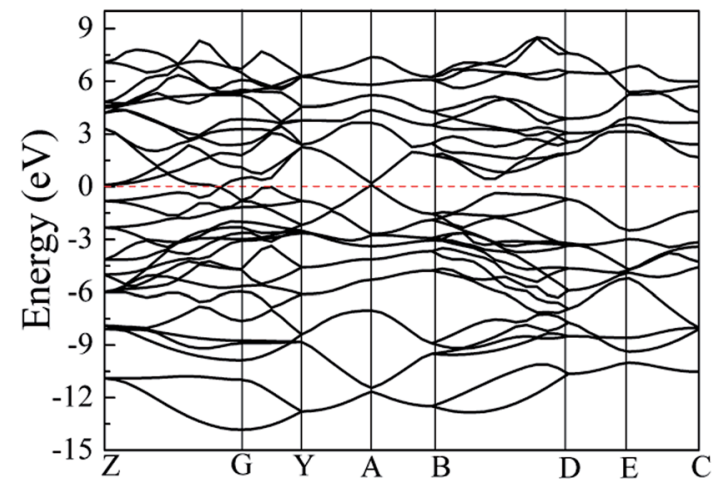

(a) $\mathrm{MnB}_{4}$-type $(\mathrm{P} 4 / \mathrm{mbm})$

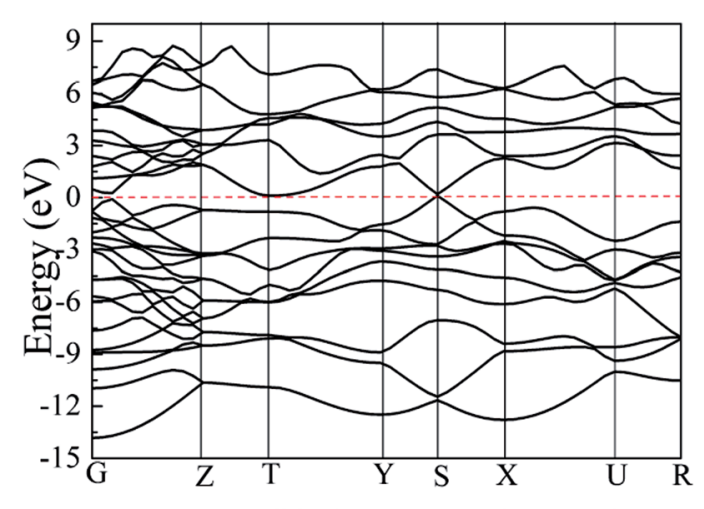

(b) $\mathrm{CrB}_{4}$-type (Immm)

Fig. 9 Calculated band structure of $\mathrm{MoB}_{4}$, (a) $\mathrm{MnB}_{4}$-type structure and (b) $\mathrm{CrB}_{4}$-type structure, respectively.

(see Fig. 1). Therefore, we suggest that the hardness of transition metal borides is also determined by the variation of $c /$ $a$ ratio.

On the other hand, transition metal borides exhibit a degree of metallic behavior in comparison to other superhard materials. To examine their electronic properties, Fig. 9 shows the calculated band structure of $\mathrm{MoB}_{4}$ with $\mathrm{MnB}_{4}$-type and $\mathrm{CrB}_{4}{ }^{-}$ type structures. The horizontal dotted line indicates the Fermi level $\left(E_{\mathrm{F}}\right)$. It is observed that there is the electronic overlap between the top of the valence band and the conduction band, implying that $\mathrm{MoB}_{4}$ also shows the electronic properties. This result is similar to other TMBs.

\section{Conclusion}

In summary, our $a b$ initio calculations have revealed that $3 \mathrm{D}-$ network B-B covalent bond can effectively enhance the Vickers hardness of TMBs. The hardening mechanism of TMBs is related to the $c / a$ ratio and $B / G$ ratio. To demonstrate the idea, we use the ab initio calculations to systematically investigate the structural stability, structural information, elastic modulus, Vickers hardness, electronic properties and electronic structure of $\mathrm{MoB}_{4}$. Four possible $\mathrm{MoB}_{4}$ tetraborides are predicted. According to the formation enthalpy and phonon dispersion, we deny $\mathrm{MoB}_{4}$ with $\mathrm{WB}_{4}$-type hexagonal structure and predict 
new $\mathrm{MoB}_{4}$ structures $(\mathrm{C} 2 / \mathrm{m}$ and $\mathrm{Immm})$. The calculated lattice parameters of $\mathrm{MnB}_{4}$-type structure are $a=5.785 \AA$, $b=5.767 \AA$ and $c=2.959 \AA$, respectively. The lattice parameters of $\mathrm{CrB}_{4}$ type structure are $a=5.785 \AA, b=5.767 \AA$ and $c=2.959 \AA$, respectively. In particular, we find that the calculated Vickers hardness of $\mathrm{MnB}_{4}$-type structure and $\mathrm{CrB}_{4}$-type structure is 41.3 GPa and 40.0 GPa, respectively. The calculated chemical bonding shows that the high hardness of $\mathrm{MoB}_{4}$ is attributed to the 3D-network B-B covalent bonds. With increasing pressure, the Vickers hardness of $\mathrm{MoB}_{4}$ decreases, in contrary to the elastic modulus of $\mathrm{MoB}_{4}$ increases. This result is similar to the other TMBs. We suggest that the trend of hardness derives from the $B / G$ ratio and $c / a$ ratio. Therefore, we predict that $\mathrm{MoB}_{4}$ is a new superhard material.

\section{Conflicts of interest}

There are no conflicts to declare.

\section{Acknowledgements}

This work is supported by National Natural Science Foundation of China (Grant No. 51564025), State Key Laboratory of Advanced Technology for Comprehensive Utilization of Platinum Metals (Grant No. SKL-SPM-201816) and the important Project of Nature Science Foundation of Yunnan (No. 2017FA029). We also thank Lady Yun Zheng for discussion.

\section{References}

1 G. Akopov, M. T. Yeung and R. B. Kaner, Adv. Mater., 2017, 29, 1604506.

2 S. Carenco, D. Portehault, C. Boissiere, N. Mezailles and C. Sanchez, Chem. Rev., 2013, 113, 7981-8065.

3 J. P. Scheifers, Y. Zhang and B. P. T. Fokwa, Acc. Chem. Res., 2017, 50, 2317-2325.

4 Y. Pan and B. Zhou, Ceram. Int., 2017, 43, 8763-8768.

5 B. Albert and H. Hillebrecht, Angew. Chem., Int. Ed., 2009, 48, 8640-8668.

6 L. P. Ding, P. Shao, F. H. Zhang, C. Lu, L. Ding, S. Y. Ning and X. F. Huang, Inorg. Chem., 2016, 55, 7033-7040.

7 S. Wei, D. Li, Y. Lv, Z. Liu, F. Tian, D. Duan, B. Liu and T. Cui, J. Alloys Compd., 2016, 688, 1101-1107.

8 B. Chu, D. Li, K. Bao, F. Tian, D. Duan, X. Sha, B. Liu and T. Cui, J. Alloys Compd., 2014, 617, 660-664.

9 Y. Pan, H. Huang, X. Wang and Y. Lin, Comput. Mater. Sci., 2015, 109, 1-6.

10 D. Koumoulis, C. L. Turner, R. E. Taylor and R. B. Kaner, J. Phys. Chem. C, 2016, 120, 2901-2907.

11 Y. Zhang, L. Wu, B. Wan, Y. Zhao, R. Gao, Z. Li, J. Zhang, H. Gou and H. K. Mao, Phys. Chem. Chem. Phys., 2016, 18, 2361-2368.

12 B. J. Suh, X. Zong, Y. Singh, A. Niazi and D. C. Johnston, Phys. Rev. B: Condens. Matter Mater. Phys., 2007, 76, 144511.

13 A. Latini, J. V. Rau, R. Teghil, A. Generosi and V. R. Alberini, ACS Appl. Mater. Interfaces, 2010, 2, 581-587.
14 Z. Li, D. Zheng, Z. Ding, Y. Li, B. Yao, Y. Li, X. Zhao, G. Yu, Y. Tang, W. Zheng and X. Liu, Mater. Res. Bull., 2016, 74, 188-191.

15 Y. Pan and Y. Lin, JOM, 2017, 69, 2009-2013.

16 H. Y. Niu, J. Q. Wang, X. Q. Chen, D. Z. Li, Y. Y. Li and P. Lazar, Phys. Rev. B: Condens. Matter Mater. Phys., 2012, 85, 144116.

17 G. Akopov, M. T. Yeung, C. L. Turner, R. Mohammadi and R. B. Kaner, J. Am. Chem. Soc., 2016, 138, 5714-5721.

18 J. B. Levine, J. B. Betts, J. D. Garrett, S. Q. Guo, J. T. Eng, A. Migliori and R. B. Kaner, Acta Mater., 2010, 58, 1530-1535.

19 A. G. V. D. Geest and A. N. Kolmogorov, CALPHAD: Comput. Coupling Phase Diagrams Thermochem., 2014, 46, 184-204.

20 X. Zhang, E. Zhao, Z. Wu, K. Li and Q. Hou, Comput. Mater. Sci., 2014, 95, 377-383.

21 L. P. Ding, X. Y. Kuang, P. Shao and X. F. Huang, Inorg. Chem., 2014, 53, 3471-3479.

22 A. L. Ivanovskii, Prog. Mater. Sci., 2012, 57, 184-228.

23 Q. F. Gu, G. Krauss and W. Steurer, Adv. Mater., 2008, 20, 3620-3626.

24 M. T. Yeung, J. Lei, R. Mohammadi, C. L. Turner, Y. Wang, S. H. Tolbert and R. B. Kaner, Adv. Mater., 2016, 28, 69936998.

25 G. Akopov, M. T. Yeung, Z. C. Sobell, C. L. Turner, C. W. Lin and R. B. Kaner, Chem. Mater., 2016, 28, 6605-6612.

26 R. Mohammadi, C. L. Turner, M. Xie, M. T. Yeung, A. T. Lech, S. H. Tolbert and R. B. Kaner, Chem. Mater., 2016, 28, 632637.

27 A. Knappschneider, C. Litterscheid, D. Dzivenko, J. A. Kurzman and R. Sechadri, Inorg. Chem., 2013, 52, 540542.

28 X. Zhang, J. Qin, X. Sun, Y. Xue, M. Ma and R. Liu, Phys. Chem. Chem. Phys., 2013, 15, 20894-20899.

29 Q. Li, D. Zhou, W. Zheng, Y. Ma and C. Chen, Phys. Rev. Lett., 2015, 115, 185502.

30 Q. Tao, D. Zheng, X. Zhao, Y. Chen, Q. Li, Q. Li, C. Wang, T. Cui, Y. Ma, X. Wang and P. Zhu, Chem. Mater., 2014, 26, 5297-5302.

31 Y. Liang, Z. Fu, X. Yuan, S. Wang, Z. Zhong and W. Zhang, Europhys. Lett., 2012, 98, 66004.

32 C. Zang, H. Sun and C. Chen, Phys. Rev. B: Condens. Matter Mater. Phys., 2012, 86, 180101.

33 S. Wang, X. Yu, J. Zhang, Y. Zhang, L. Wang, D. He and Y. Zhao, Journal of Superhard Materials, 2014, 36, 279-287.

34 K. I. Portnoi, V. M. Romashov and L. N. Burobina, Powder Metall. Met. Ceram., 1970, 9, 577-580.

35 S. Andersson and J. O. Carlsson, Acta Chem. Scand., 1970, 24, 1791-1799.

36 D. M. Ceperley and B. J. Alder, Phys. Rev. Lett., 1980, 45, 566569.

37 M. D. Segall, P. J. D. Lindan, M. J. Probert, C. J. Pickard, P. J. Hasnip, S. J. Clark and M. C. Payne, J. Phys.: Condens. Matter, 2002, 14, 2717-2744.

38 D. Vanderbilt, Phys. Rev. B: Condens. Matter Mater. Phys., 1990, 41, 7892-7895.

39 Y. Pan, Y. Lin, H. Wang and C. Zhang, Mater. Des., 2015, 86, 259-265. 
40 Y. Pan, J. Zhang, C. Jin and X. Chen, Mater. Des., 2016, 108, 13-18.

41 X. Q. Chen, H. Y. Niu, D. Z. Li and Y. Y. Li, Intermetallics, 2011, 19, 1275-1281.

42 Y. Pan, P. Mao, H. Jiang, Y. Wan and W. Guan, Ceram. Int., 2017, 43, 5274-5282.

43 Y. Pan and W. M. Guan, Phys. Chem. Chem. Phys., 2017, 19, 19427-19433.

44 M. Zhang, H. Wang, H. Wang, T. Cui and Y. Ma, J. Phys. Chem. C, 2010, 114, 6722-6725.

45 M. Zhang, H. Yan, G. ZHang and H. Wang, J. Phys. Chem. C, 2012, 116, 4293-4297.

46 M. Zhang, H. Yan, Q. Wei and H. Wang, Comput. Mater. Sci., 2013, 68, 371-378.
47 T. Lundstrom and I. Rosenberg, J. Solid State Chem., 1973, 6, 299-305.

48 M. Wang, Y. W. Li, T. Cui, Y. M. Ma and G. T. Zou, Appl. Phys. Lett., 2008, 93, 101905.

49 Y. Pan, Y. H. Lin, M. Wen and Q. N. Meng, RSC Adv., 2014, 4, 63891-63896.

50 Y. Pan, Y. Lin, Q. Xue, C. Ren and H. Wang, Mater. Des., 2016, 89, 676-683.

51 M. Mazdziarz and T. Moscicki, Mater. Chem. Phys., 2016, 179, 92-102.

52 X. Li, Y. Tao and F. Peng, J. Alloys Compd., 2016, 687, 579585. 